\title{
For me or for others? The better-than-average effect and negative feelings toward average others during the COVID-19 pandemic
}

\author{
Min Young Kim ${ }^{1} \cdot$ Kyueun $\mathrm{Han}^{2}$
}

Accepted: 16 November 2021

(c) The Author(s), under exclusive licence to Springer Science+Business Media, LLC, part of Springer Nature 2021

\begin{abstract}
During the first outbreak of the coronavirus disease 2019 (COVID-19), many people expressed hatred toward others whom they believed were responsible for the situation. Such increase in negative affect could be resultant of the better-than-average effect (BTAE), which refers to the phenomenon of believing that one is superior to average others. This study investigated the relationship between the BTAE and emotional valence toward others and tested whether the relationship was moderated by allocentric goals (i.e., concerned with the interests of others rather than themselves) and culture. Participants from the U.S. $(N=210)$ and South Korea $(N=214)$ were asked about their perceptions on whether they were better than others at preventing the COVID-19 infection, how they felt about others regarding COVID-19, and for whom they were preventing COVID-19. The results indicated that people showing more BTAE in relation to preventing the COVID-19 infection reported more negative emotional valence toward others, but the relationship was moderated by allocentric goals. In particular, the U.S. participants with higher allocentric goals reported less negatively valenced emotions, while the same was not found in Korean participants. The findings suggest the power of allocentric goals in diminishing the BTAE in some cultures, which may possibly explain the negative emotions some people experience when following social distancing rules.
\end{abstract}

Keywords Better than average effect $\cdot$ Self-enhancement $\cdot$ Allocentric goals $\cdot$ Cultural differences

\section{Introduction}

The first outbreak of the coronavirus disease 2019 (COVID19) caused not only significant health adversities among people, some even resulting in death, but also affected diverse areas of their daily lives, including social and emotional aspects (Holmes et al., 2020). During the COVID-19 pandemic, many people have been at risk of experiencing severe emotional distress, depression, and anger (Huang $\&$ Zhao, 2020; Montemurro, 2020). Among such negative emotions, one prominent social phenomenon is increased anger and hatred toward people in specific groups who some people believe are responsible for the spread of COVID-19 (Xu et al., 2021). The media has reported discrimination and verbal abuse targeting groups such as Asians and migrant

Kyueun Han

kyueun.han@smu.ac.kr

1 Department of Psychology, Keimyung University, Daegu, South Korea

2 College of General Studies, Sangmyung University, Seoul 03016, South Korea workers across the United States (U.S.) and European countries during COVID-19 (e.g., Gottleib \& LeBas, 2020). For instance, in the U.S. in March 2021, a 21-year-old man killed eight people, including six Asian-American women, in Atlanta, which was concluded to be a hate crime targeting this population. Further, people have expressed negative feelings not only toward specific group members but also toward unspecified, ungrouped others during the COVID19 pandemic (Strochlic, 2020). Why do people experience negative emotions toward others in this life-threatening situation? To address this question, the current study explored the better-than-average effect (BTAE), which forms the basis of cognitions related to one's superiority over others (Zell et al., 2020) and further engenders feelings of supremacy (Hage, 2012). The impact of individuals' allocentric and egocentric goals was also assessed.

\section{The Better-Than-Average Effect and Self-Enhancement}

The BTAE is a social comparative bias in which people evaluate their performance or abilities more favorably than they 
do those of average others (Alicke et al., 1997). For example, most people overestimate their grammatical ability (Kruger \& Dunning, 1999) and morality (Tappin \& McKay, 2017), and underestimate their personal risk of disease (Rothman et al., 1996). However, since not all individuals are better than average, the BTAE shows that most people are biased toward optimistic self-perceptions (Taylor \& Brown, 1988).

Research suggests that the BTAE operates under the mechanisms of self-enhancement (Alicke, 1985; Brown, 1986; Sedikides \& Strube, 1997). With the assumption that concern for the self is the most fundamental human motivation (Broad, 1949), it has been suggested that people are motivated to perceive and evaluate themselves favorably to maintain a positive self-perception (Alicke \& Govorun, 2005). Among self-enhancement mechanisms, researchers have suggested two by which self-enhancement may be maintained: cognitive and situational. ${ }^{1}$

According to the cognitive perspective, people selectively perceive information or attend to comparison targets that confirm a positive self-image. Research suggests that people who have such biases retrieve favorable information about themselves from memory (Sedikides \& Gregg, 2008). Further, researchers have found that people tend to focus on themselves rather than on average others (i.e., focalism), weigh highly their own desirable behaviors or characteristics (i.e., egocentrism), and evaluate others in a way that promotes favorable self-perceptions (Alicke et al., 1997). Such cognitive strategies lead people to believe they are superior to others.

Based on the cognitive approach to understanding selfenhancement mechanisms, the BTAE provides a possible explanation for emotions toward groups during COVID-19. From this perspective, people would selectively perceive positive information about their own COVID-19 preventive behaviors to feel good about themselves (e.g., Swann Jr \& Brooks, 2012). People may have a better recollection of times when they follow COVID-19 prevention rules than when they violate such rules. In contrast, people may be more likely to perceive when others violate the rules than when others follow the rules. Consequently, people may tend to believe that they follow COVID-19 prevention rules more strictly than average others. Accordingly, it was hypothesized that people who believed that they were better at preventing the COVID-19 infection (e.g., practicing good hygiene and social/physical distancing) would express more negative affect toward others who did not engage in the COVID-19 prevention measures well (Hypothesis 1).

The situational perspective suggests that some aspects of situations lead people to boost or diminish the BTAE for

\footnotetext{
1 This is also referred to as a motivational approach (Zell et al., 2020).
}

the sake of self-enhancement. Consistent with the situational perspective, the magnitude of the BTAE varies according to context. For example, if people perceive that the context is abstract or vague, they exhibit a greater BTAE (Dunning et al., 1989; Logg et al., 2018; Van Lange \& Sedikides, 1998). In addition, people exhibit a greater BTAE if they perceive that the context references controllable positive traits or personally and culturally important entities (Alicke, 1985; Brown, 2012; Sedikides et al., 2003). These findings suggest that context plays a major role in promoting a superior self-perspective (Zell et al., 2020).

From the situational perspective, people would exhibit the BTAE if situations are personally and culturally important (e.g., Brown, 2012; Sedikides et al., 2003), especially when it is not controllable (Alicke, 1985; Dunning et al., 1989), such as with the COVID-19 pandemic or the threat of war. As people are likely to exhibit a high BTAE during the COVID-19 pandemic, they would attribute positive outcomes to themselves and epidemic spread to others (Bradley, 1978; Zuckerman, 1979), which could cause negative feelings toward others or outgroups.

The current study investigated the situational factors underlying behavioral goals. People often exhibit a selfserving bias and behave in egocentric ways; however, most people also have concern for others and can behave in allocentric ways (Crocker et al., 2017). Evolutionary psychology posits that altruistic behaviors are not truly altruistic; rather, behaviors such as helping or caring for one's offspring or kin are ultimately initiated by self-centered goals (e.g., Murray et al., 2006; Neel et al., 2016). In contrast, researchers in the field of social motivation have suggested that, as a component of human nature, people have innate, genuine motives for prosocial, allocentric goals (Mikulincer $\&$ Shaver, 2010; Shaver et al., 2010). People can engage in prosocial behavior with the aim of benefiting the well-being of others (Mikulincer \& Shaver, 2010) or even of humankind (Sprecher \& Fehr, 2005). Such behaviors are observed among both adults and children (Li et al., 2013).

Given that people have motives not only concerning themselves (i.e., egocentric goals) but also with respect to others (i.e., allocentric goals), the BTAE can be moderated by conflict between one's primary and secondary goals. In a review of literature on prosocial motives, Mikulincer and Shaver (2010) suggested that allocentric goals are minimized or intensified by the extent to which an individual holds selfish attitudes and values. Such a moderation effect, in turn, can affect people's emotions toward average others. Studies suggest that allocentric goals, which are also termed "otherishness" (Crocker et al., 2017; Grant, 2014), relate to more positive emotions, greater life satisfaction, and lower depression compared to self-focused goals (Aknin et al., 2013; Dunn et al., 2008; Wiwad \& Aknin, 2017). However, 
egocentric goals, such as collective narcissism, reflect hostile intentions toward outgroups (Golec de Zavala et al., 2019).

An integrative framework that includes both the cognitive and situational approaches to the BTAE might facilitate a more profound understanding of the social issue of hatred toward others during the COVID-19 pandemic. Specifically, it was hypothesized that the predominant goal would subtly alter the impact of the BTAE on negative feelings toward average others (Hypothesis 2). Although individuals in general may think they perform better than others at preventing COVID-19 infection in daily life (e.g., practicing good hygiene and social/physical distancing), if the underlying motivation is allocentric rather than egocentric, such individuals would express relatively less negative emotion toward others who they consider to be performing poorly at preventing the COVID-19 infection.

\section{Culture and Allocentric Goals}

The concept of allocentric goals could differ across cultures. Specifically, whether allocentric goals would have the same effects in individualistic and collectivistic cultures is another topic of interest. People in individualistic cultures tend to separate the self from the social context and emphasize autonomy and independence, which is called independent self-construal (Markus \& Kitayama, 1991). However, people in collectivistic cultures tend to interpret the self as part of the social context and consider themselves to be reflections of the characteristics of their society, which is called interdependent self-construal. In this sense, there is likely to be a distinct boundary between the self and others (or between the in-group and outgroup) in individualistic cultures because of independent self-construal, whereas in collectivistic cultures, this boundary is likely to be ambiguous or overlapping because of interdependent self-construal (Fiske et al., 1998). Thus, relative to those with interdependent self-construal, people with independent self-construal may more clearly separate their own interests from those of others.

Self-construal theory suggests that altruism or allocentric goals can be more salient for independent rather than interdependent individuals. From the altruistic perspective, researchers have suggested that independent individuals are primarily concerned with what is beneficial to them (De Cremer \& van Lange, 2001); however, this does not necessarily mean they are selfish. Interdependent individuals may believe that what benefits others will eventually benefit them as well (Finkelstein, 2010). The lack of a clear distinction between self-interests and the interests of others may lead interdependent individuals to perceive allocentric goals as being more conventional, rather than salient, behavioral goals. If that is the case, setting allocentric goals would have less effect on the behavior of individuals with interdependent self-construal than on those with independent self-construal.

Therefore, it was hypothesized that the moderating effect of altruism on the relationship between the BTAE and the predominance of allocentric goals would differ across cultures. Specifically, the predominance of allocentric goals would be less likely to affect the relationship between the BTAE and negative emotions toward others in cultures with interdependent self-construal than in those with independent self-construal (Hypothesis 3).

Overall, this study had three objectives: a) to study the influence of the BTAE on negative emotion generation; $b$ ) to analyze the moderating role of egocentric/allocentric goals in this relationship; and c) to compare this relationship and its effects between cultures.

\section{Methods}

\section{Participants}

A priori power analyses using $G^{*}$ power (Faul et al., 2009) indicated that the sample size needed to detect an effect size of $d=.15$ with $95 \%$ power was 146 individuals in each group. To sufficiently detect the hypothesized effect size, 210 participants were recruited from the U.S. $\left(M_{\text {age }}=36.47\right.$, $S D_{\text {age }}=10.68 ; 34.8 \%$ female) via Amazon's Mechanical Turk (www.MTurk.com). Participants were born in or had resided for more than 20 years in the U.S. $\left(M_{\text {years }}=33.75\right.$, $\left.S D_{\text {years }}=11.95\right)$. All participants received monetary compensation (\$1.00) upon completion of the survey. Additionally, 214 participants were recruited $\left(M_{\text {age }}=25.24, S D_{\text {age }}=8.80\right.$; $69.3 \%$ female) online in Korea. Participants were compensated by course credit or a monetary reward of 1000 Korean won for their participation.

\section{Procedures}

The survey was conducted online and introduced as a study of the COVID-19 pandemic and associated changes in daily life. Participants who volunteered for the survey approved the online consent form and completed the survey, including items on the BTAE, behavioral goals, and emotional valence toward others. The survey also included questions on demographic information and duration (in months) since the COVID-19 outbreak in the respondent's local community to be used as control variable in the analysis. For the two language versions, all items were translated by a bilingual person, and another bilingual person reviewed and approved the translation via a forward- and back-translation process. An ethics committee for human research approved the study protocols. 
Table 1 Summary of means, standard deviations, and correlations in the U.S. and Korean samples

\begin{tabular}{|c|c|c|c|c|c|c|c|c|}
\hline Sample & Variables & $M$ & $S D$ & 1 & 2 & 3 & 4 & 5 \\
\hline \multirow[t]{6}{*}{ U.S. } & 1. Gender ${ }^{\mathrm{a}}$ & 1.35 & 0.48 & - & & & & \\
\hline & 2. Age & 36.47 & 1.48 & .08 & - & & & \\
\hline & 3. Months of COVID-19 & 2.53 & 0.83 & .11 & .02 & - & & \\
\hline & 4. $\mathrm{BTAE}^{\mathrm{c}}$ & 0.64 & 2.42 & .08 & .01 & $.25 * *$ & - & \\
\hline & 5. Predominance of allocentric goals & 37.81 & 27.73 & .11 & -.07 & -.04 & -.07 & - \\
\hline & 6.Emotional valence toward others & 2.87 & 5.56 & .08 & .03 & $-.15^{*}$ & $-.41 * *$ & -.08 \\
\hline \multirow[t]{6}{*}{ Korea } & 1. Gender ${ }^{\mathrm{a}}$ & 1.74 & 0.49 & - & & & & \\
\hline & 2. Age & 25.24 & 8.81 & -.02 & - & & & \\
\hline & 3. Months of COVID- $19^{\mathrm{b}}$ & 3.64 & 0.68 & .05 & .02 & - & & \\
\hline & 4. $\mathrm{BTAE}^{\mathrm{c}}$ & 1.75 & 2.16 & .04 & -.07 & .03 & - & \\
\hline & 5. Predominance of allocentric goals & 28.24 & 36.46 & .07 & $.20 * *$ & .04 & $-.19 * *$ & - \\
\hline & 6.Emotional valence toward others & -5.00 & 3.98 & -.08 & $.16^{*}$ & .07 & $-.29 * *$ & .09 \\
\hline
\end{tabular}

${ }^{\mathrm{a}}$ Coded as male $=1$ and female $=2$; ${ }^{\mathrm{b}}$ Coded as less than 1 month $=1,1$ to 3 months $=2,3$ to 6 months $=3$, longer than 6 months $=4 ;^{\mathrm{c}}=$ the better than average effect; $* * *<.01 . * p<.05$

\section{Measures}

The Better-than-Average Effect BTAE was assessed using two questions concerning participants' self-evaluation and evaluation of others. In particular, participants were asked to indicate the degree to which they follow the hygiene and social/physical distancing rules and the degree to which they feel others follow the rules, using a scale ranging from 0 (never) to 10 (follow all the time). The BTAE score was calculated by subtracting the rating of the evaluation of others from the self-evaluation rating. Participants with BTAE scores above 0 were considered to exhibit the BTAE.

Predominance of Allocentric Goals Participants were asked their motives behind following hygiene and social distancing rules. To assess the relative importance across dissimilar behavioral goals of participants, they were asked to assign a percentage to five categories: "For my own health," "For the health of my family," "For the local community," "For the survival and health of all humanity," and "other reasons." Participants were instructed that the total must sum to 100. The item "For my own health" represented egocentric goals and "For the health of my family," "For the local community," and "For the survival and health of all humanity" represented allocentric goals, respectively. To assess the predominance of allocentric goals, the score for the item measuring egocentric goals was subtracted from that for the items measuring allocentric goals.

Emotional Valence toward Others Participants were asked to indicate the degree to which they felt emotions regarding individuals who do not follow social/physical distancing, using a scale from -10 (negative emotions), through 0 (neutral), to 10 (positive emotions).
Months since COVID-19 Outbreak Participants were asked to indicate the duration that their personal life had been affected by COVID-19 on a scale from 1 (less than 1 month) to 4 (longer than 6 months).

\section{Analysis}

It was predicted that the level of the BTAE would be associated with negative feelings toward others in related domains (Hypothesis 1). To test this hypothesis, correlation analysis was used. It was further tested if the association between the BTAE and negative emotions toward others was moderated by the predominance of allocentric goals (Hypothesis 2) across cultural groups (Hypothesis 3 ). To test these hypotheses, moderation analysis was used, via the SPSS PROCESS macro created by Preacher and Hayes (2004) with centered variables. The analysis adjusted for three covariates: age (calculated by subtracting birth year from 2020), gender $($ male $=1$, female $=2$ ), and the duration of COVID19 impact (less than 1 month $=1,1$ to 3 months $=2,3$ to 6 months $=3$, longer than 6 months $=4$ ).

\section{Results}

\section{Relationship between the BTAE and Valence of Emotions toward Others}

BTAE ratings above 0 were present for $51.4 \%$ of the U.S. sample and $66.4 \%$ of the Korean sample. Descriptive statistics and correlations are summarized in Table 1. The results of the correlation analysis revealed that the higher the BTAE, the more negative emotions toward others in both 


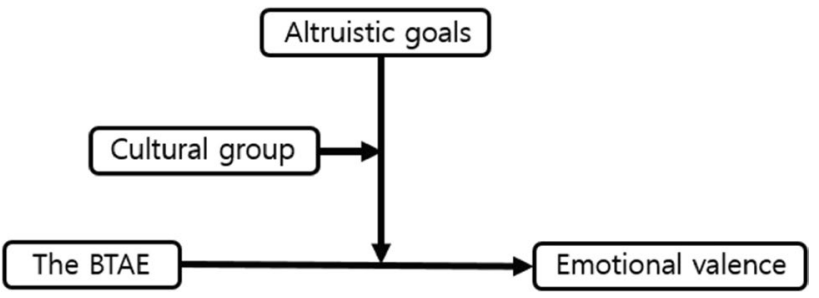

Fig. 1 A conceptual model of the two moderators described in Hypothesis 3 $p=.004)$, while in the Korean sample, the effect was not significant $(\beta=-.00, p=.870$; Table 3$)$. Figure 2 illustrates details of the variation of the moderation effect between cultural groups. In the U.S. sample, among individuals with low predominance of allocentric goals $(-1 S D)$, as they perceived that they performed better than others (higher BTAE), their emotions toward others changed from positive to considerably negative. Among individuals with high predominance of allocentric goals $(+1 S D)$, as they perceived that they performed worse or similar to others (lower BTAE), their emotions toward others changed from
Table 2 Results of moderation analyses of emotional valence toward others by cultural group

\begin{tabular}{lllllllll}
\hline & & & & & & \multicolumn{3}{c}{$95 \%$ CI } \\
\cline { 5 - 8 } & Predictors & Coeff. & $S E$ & $T$ & $p$ & Low & High \\
\hline $\begin{array}{l}R^{2}=.499, F(9,412)=41.042, \\
p<.001\end{array}$ & BTAE & -.506 & .147 & -3.455 & .001 & -.795 & -.218 \\
& Goals ${ }^{\mathrm{a}}$ & .003 & .008 & .404 & .687 & -.013 & .020 \\
& BTAE $\times$ Goals & -.001 & .004 & -.164 & .870 & -.007 & .006 \\
& Group & 6262 & .625 & 10.022 & $<.001$ & 5.034 & 7.490 \\
& BTAE $\times$ Group & -.557 & .202 & -2.765 & .006 & -.953 & -.161 \\
& Goals $\times$ Group & .005 & .014 & .364 & .716 & -.022 & .033 \\
& BTAE $\times$ Goals $\times$ Group & .012 & .005 & 2.307 & .022 & .002 & .023 \\
& Gender & -.724 & .456 & -1.589 & .113 & -1.619 & .172 \\
& Age & .041 & .022 & 1.835 & .067 & -.003 & .085 \\
& Months of COVID-19 & -.003 & .292 & -.010 & .992 & -.577 & .572 \\
\hline
\end{tabular}

${ }^{\mathrm{a}}$ Goals $=$ the predominance of allocentric goals the U.S. $(r=-.41, p<.001)$ and Korean $(r=-.29, p<.001)$ samples, which supports Hypothesis 1.

\section{Predominance of Allocentric Goals Moderating the Association between the BTAE and Negative Emotions}

Two possible moderators of the association between the BTAE and negative emotions toward others were tested using Model 3 of the PROCESS macro (Fig. 1). In the model, the predominance of allocentric goals (i.e., egocentric goals subtracted from allocentric goals) and cultural sample (i.e., U.S. and Korean samples) were entered as two moderators, BTAE as a predictor, emotional valence as an outcome, and age, gender, and months of COVID19 as covariates. The results of the moderation model are summarized in Table 2. In the total sample, the moderating effect of the predominance of allocentric goals on the association between the BTAE and emotional valence was not significant ( $\beta=-.001, p=.870)$; thus, Hypothesis 2 was not supported.

However, the significance of the predominance of allocentric goals as a moderator depended on the sample $(\beta=.01, p=.022)$. In the U.S. sample, the moderating effect of behavioral goals was significant $(\beta=.01$,
Table 3 Test of conditional BTAE $\times$ Goals interaction by cultural group

\begin{tabular}{llllll}
\hline Group & Effect & $F$ & df1 & df2 & $p$ \\
\hline U.S. sample & .012 & 9.307 & 1 & 414 & .004 \\
Korean sample & -.001 & 0.027 & 1 & 394 & .870 \\
\hline
\end{tabular}

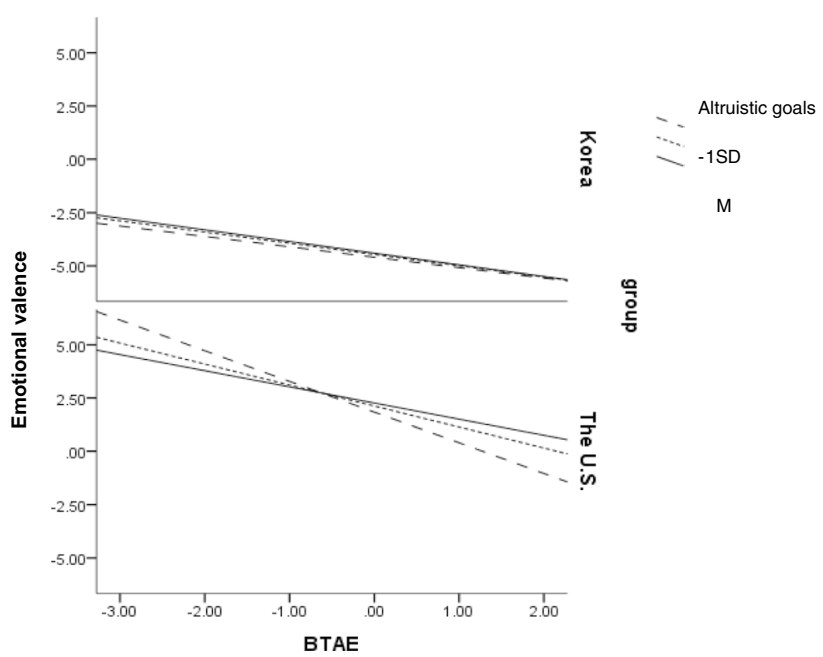

Fig. 2 The moderation model of the study between cultural samples 
positive to slightly negative; the slope of the relationship was shallower among people with high predominance of allocentric goals versus those with less altruistic goals. In the Korean sample, as individuals perceived that they performed better than others (higher BTAE), their emotions toward others changed from positive to considerably negative, but the slope did not vary according to the level of altruistic goals. Overall, the results support Hypothesis 3.

\section{Discussion}

Since the COVID-19 pandemic began to affect daily life, a global wave of negatively valenced emotions became evident, the target of which was others to whom epidemic spread was attributed (Xu et al., 2021). The current study tested if a cognitive bias, namely the BTAE and related behavioral goals, could explain people's negative emotions expressed toward others. Pervasive negative emotions toward others that emerged during the COVID-19 pandemic could possibly be explained by various psychological mechanisms, such as attribution bias or in-group versus outgroup bias, among which the present research investigated the BTAE on negative feelings toward others in an out-of-laboratory situation.

In this study, the BTAE accounted for negative feelings toward others. In addition, this association was moderated by the predominance of allocentric behavioral goals, depending on the cultural group. Specifically, low predominance of allocentric goals intensified the BTAE on expressing negative feelings toward others, while high predominance of allocentric goals reduced the BTAE in the U.S. sample. The finding is consistent with previous literature on the interaction between egocentric motives and altruistic behavior (e.g., Mikulincer \& Shaver, 2010).

The findings imply that allocentric goals can sometimes affect psychological processes underlying self-enhancement. Self-enhancement has been considered an unalterable primary motive for all human behavior (Dufner et al., 2019; Hepper et al., 2013; Sedikides \& Alicke, 2019). Consistent with research on prosocial behavior, however, findings of this study suggest that people have motives not only concerning themselves but also with respect to others. In this study, the impact of such a motive appeared to be reduced among individuals with allocentric behavioral goals rather than egocentric goals in the U.S. sample. Specifically, even during a life-threatening experience, such as the COVID-19 pandemic, people can exhibit low BTAE and behave in allocentric ways if they have concern for others (e.g., Crocker et al., 2017). A classic model of goal-directed behavior (Ajzen \& Madden, 1986) also supports this idea in that allocentric goal setting can result in displays of prosocial behavior over and above self-enhancement motives (e.g., Aknin et al., 2019; Wentzel et al., 2004).

The findings provide a plausible explanation for the behavior of people during the COVID-19 pandemic. The experts investigating impacts of the pandemic suggest allocentric behavior as a key to promote voluntary self-isolation or social withdrawal, which in turn could result in the prevention of mutation spread and the eventual end of the pandemic (Bouayed et al., 2021; Jordan et al., 2020). However, the psychological mechanisms underlying the suggested process remains unexplored. The present research contributed to fill the gap in the literature with experimental data; the study demonstrates that people with higher allocentric motive tend to experience less negatively-valenced emotions towards others, even when they believe that they follow social distancing rules more than others. Such emotional responses from people with high allocentric motives may help them better adhere to voluntary self-isolation and measures for the prevention of virus spread. Thus, depending on the culture, allocentric motives can serve to prevent the spread of the virus and gradually end the pandemic.

Interestingly, such a moderation effect was not found in the Korean sample in this study. Thus, it may be an overgeneralization to conclude that allocentric goals could universally contribute to ending the pandemic via engaging in voluntary self-isolation and virus spread preventive measures. This finding does not necessarily suggest that Koreans do not have self-enhancement motives. As suggested by cultural psychologists, motives could operate in different ways between Eastern and Western cultures (e.g., Bai et al., 2017). It is possible that behaviors based on allocentric goals are not valued or helpful for self-enhancement in collectivistic cultures (e.g., South Korea), where competitive advantages are considered a virtue in interpersonal relationships (Liu et al., 2019). In addition, self-construal theory suggests that the separation of self and others is ambiguous in collectivistic culture (Fiske et al., 1998; Markus \& Kitayama, 1991); therefore, the concept or meaning of allocentric goals can function differently in independent cultural contexts. As highlighting allocentric motives may not be helpful to curtail the pandemic in some cultures, further research is necessary to investigate the specific motives or goals that guide people's helping behaviors to end the pandemic across various cultures. Practical implications of this study also include providing information regarding ways to approach people who are experiencing negative feelings toward others. For instance, this study could help identify those expressing negative feelings toward Asians due to beliefs that this group is responsible for the spread of COVID-19. According to the findings of this study, the BTAE and negative feelings are stronger among people who pursue relatively less allocentric goals compared to egocentric goals. One of the preliminary ways to intervene against negative feelings toward others 
in society during the COVID-19 pandemic could be via understanding people's cognitive biases, such as the BTAE, and their allocentric goals. Ultimately, the practical implications from this study could be applied to the development of programs to address bias caused by the BTAE and related negative attitudes at the community level.

One of the limitations of this study pertains to a measurement issue. Single items were used when assessing main variables, such as emotional valence toward average others, because the study was designed to detect overall negative feelings when people were thinking of others. However, with single items, potential measurement equivalence across samples cannot be tested. In future studies, multiple items should be presented to enable the assessment of measurement equivalence across cultural samples. Further, in the current study, participants were asked how negatively they felt toward individuals. However, negative feelings are a broad construct comprised of discrete emotions, such as anger, sadness, depression, and hatred (Russell \& Barrett, 1999). Further research using multiple items to assess negative feelings could reveal which negative emotions are related to the BTAE during COVID-19.

Future studies will benefit from considering comprehensive sampling. Two samples were recruited in this study: one from the U.S. and one from Korea. As the U.S. sample was from a Western culture while the Korean sample was from an Eastern culture, this study represents preliminary research that could help inform future cultural studies. Studies of various cultures are required to enable generalization of the present findings.

Data Availability The datasets generated during and/or analyzed during the current study are available from the corresponding author on reasonable request.

\section{Declarations}

Conflict of Interest The authors declared no conflicts of interest with respect to the authorship or the publication of this article.

\section{References}

Ajzen, I., \& Madden, T. J. (1986). Prediction of goal-directed behavior: Attitudes, intentions, and perceived behavioral control. Journal of Experimental Social Psychology, 22(5), 453-474. https://doi.org/ 10.1016/0022-1031(86)90045-4

Aknin, L. B., Dunn, E. W., Whillans, A. V., Grant, A. M., \& Norton, M. I. (2013). Making a difference matters: Impact unlocks the emotional benefits of prosocial spending. Journal of Economic Behavior \& Organization, 88, 90-95. https://doi.org/10.1016/j. jebo.2013.01.008

Aknin, L. B., Whillans, A. V., Norton, M. I., \& Dunn, E. W. (2019). Happiness and prosocial behavior: An evaluation of the evidence. In J. Helliwell, R. Layard, \& J. Sachs (Eds.), World happiness report 2019 (pp. 67-85). Sustainable Development Solutions Network.

Alicke, M. D. (1985). Global self-evaluation as determined by the desirability and controllability of trait adjectives. Journal of Personality and Social Psychology, 49(6), 1621-1630. https://doi.org/ 10.1037/0022-3514.49.6.1621

Alicke, M. D., \& Govorun, O. (2005). The better-than-average effect. In M. D. Alicke, D. A. Dunning, \& J. I. Krueger (Eds.), The self in social judgment (Vol. 1, pp. 85-106). Psychology Press.

Alicke, M. D., LoSchiavo, F. M., Zerbst, J., \& Zhang, S. (1997). The person who out performs me is a genius: Maintaining perceived competence in upward social comparison. Journal of Personality and Social Psychology, 73(4), 781-789. https://doi.org/10.1037// 0022-3514.73.4.781

Bai, Y., Maruskin, L. A., Chen, S., Gordon, A. M., Stellar, J. E., McNeil, G. D., et al. (2017). Awe, the diminished self, and collective engagement: Universals and cultural variations in the small self. Journal of Personality and Social Psychology, 113(2), 185-209. https://doi.org/10.1037/pspa0000087

Bouayed, J., Hefeng, F. Q., Desai, M. S., Zhou, B., Rashi, T., Soulimani, R., \& Bohn, T. (2021). Anti-pandemic lessons and altruistic behavior from major world religions at the time of COVID-19. Brain, Behavior, and Immunity, 95, 4-6. https://doi.org/10.1016/j. bbi.2021.04.023

Bradley, G. (1978). Self-serving biases in the attribution process: A re-examination of the fact or fiction question. Journal of Personality and Social Psychology, 36, 56-71. https://doi.org/10.1037/ 0022-3514.36.1.56

Broad, C. D. (1949). Egoism as a theory of human motives. Hibbert Journal, 48, 105-114.

Brown, J. D. (1986). Evaluations of self and others: Self-enhancement biases in social judgments. Social Cognition, 4(4), 353-376. https://doi.org/10.1521/soco.1986.4.4.353

Brown, J. D. (2012). Understanding the better than average effect: Motives (still) matter. Personality and Social Psychology Bulletin, 38, 209-219. https://doi.org/10.1177/0146167211432763

Crocker, J., Canevello, A., \& Brown, A. A. (2017). Social motivation: Costs and benefits of selfishness and otherishness. Annual Review of Psychology, 68, 299-325. https://doi.org/10.1146/annur ev-psych-010416-044145

De Cremer, D., \& Van Lange, P. A. (2001). Why prosocials exhibit greater cooperation than proselfs: The roles of social responsibility and reciprocity. European Journal of Personality, 15(1_suppl), S5-S18. https://doi.org/10.1002/per.418

Dufner, M., Gebauer, J. E., Sedikides, C., \& Denissen, J. J. (2019). Self-enhancement and psychological adjustment: A meta-analytic review. Personality and Social Psychology Review, 23(1), 48-72. https://doi.org/10.1177/1088868318756467

Dunn, E. W., Aknin, L. B., \& Norton, M. I. (2008). Spending money on others promotes happiness. Science, 319(5870), 1687-1688. https://doi.org/10.1126/science.1150952

Dunning, D., Meyerowitz, J. A., \& Holzberg, A. D. (1989). Ambiguity and self-evaluation: The role of idiosyncratic trait definitions in self-serving assessments of ability. Journal of Personality and Social Psychology, 57, 1082-1090. https://doi.org/10.1037/00223514.57.6.1082

Faul, F., Erdfelder, E., Buchner, A., \& Lang, A. G. (2009). Statistical power analyses using $\mathrm{G}^{*}$ power 3.1: Tests for correlation and regression analyses. Behavior Research Methods, 41(4), 11491160. https://doi.org/10.3758/BRM.41.4.1149

Finkelstein, M. A. (2010). Individualism/collectivism: Implications for the volunteer process. Social Behavior and Personality: An International Journal, 38, 445-452. https://doi.org/10.2224/sbp. 2010.38.4.445

Fiske, A. P., Kitayama, S., Markus, H. R., \& Nisbett, R. E. (1998). The cultural matrix of social psychology. In D. T. Gilbert \& S. T. Fiske 
(Eds.), The handbook of social psychology (Vol. 2, 4th ed., pp. 915-981). McGraw-Hill.

Golec de Zavala, A., Dyduch-Hazar, K., \& Lantos, D. (2019). Collective narcissism: Political consequences of investing self-worth in the ingroup's image. Political Psychology, 40, 37-74. https://doi. org/10.1111/pops. 12569

Gottleib, J. \& LeBas, A. (2020). How the coronavirus pandemic is fueling ethnic hatred. Washington Post. Retrieved from https:// www.washingtonpost.com/politics/2020/09/18/megacities-pande mics-economic-crisis-is-fueling-ethnic-hatred/. Accessed $11 \mathrm{Mar}$ 2021

Grant, A. M. (2014). Give and take: Why helping others drives our success. Penguin.

Hage, G. (2012). White nation: Fantasies of white supremacy in a multicultural society. Routledge.

Hepper, E. G., Sedikides, C., \& Cai, H. (2013). Self-enhancement and self-protection strategies in China: Cultural expressions of a fundamental human motive. Journal of Cross-Cultural Psychology, 44, 5-23. https://doi.org/10.1177/0022022111428515

Holmes, E. A., O'Connor, R. C., Perry, V. H., Tracey, I., Wessely, S., Arseneault, L., et al. (2020). Multidisciplinary research priorities for the COVID-19 pandemic: A call for action for mental health science. The Lancet Psychiatry, 7, 547-560. https://doi.org/10. 1016/S2215-0366(20)30168-1

Huang, Y., \& Zhao, N. (2020). Generalized anxiety disorder, depressive symptoms and sleep quality during COVID-19 outbreak in China: A web-based cross-sectional survey. Psychiatry Research, 288, 112954. https://doi.org/10.1016/j.psychres.2020.112954

Jordan, J., Yoeli, E., \& Rand, D. (2020). Don't get it or don't spread it? Comparing self-interested versus prosocial motivations for COVID-19 prevention behaviors. PsyArXiv. https://doi.org/10. 31234/osf.io/yuq7x

Kruger, J., \& Dunning, D. (1999). Unskilled and unaware of it: How difficulties in recognizing one's own incompetence lead to inflated self-assessments. Journal of Personality and Social Psychology, 77, 1121-1134. https://doi.org/10.1037/0022-3514.77.6.1121

Li, Y., Li, H., Decety, J., \& Lee, K. (2013). Experiencing a natural disaster alters children's altruistic giving. Psychological Science, 24, 1686-1695. https://doi.org/10.2307/23484668

Liu, S. S., Morris, M. W., Talhelm, T., \& Yang, Q. (2019). Ingroup vigilance in collectivistic cultures. Proceedings of the National Academy of Sciences, 116(29), 14538-14546. https://doi.org/10. 1073/pnas. 1817588116

Logg, J. M., Haran, U., \& Moore, D. A. (2018). Is overconfidence a motivated bias? Experimental evidence. Journal of Experimental Psychology: General, 147, 1445-1465. https://doi.org/10.1037/ xge0000500

Markus, H. R., \& Kitayama, S. (1991). Culture and the self: Implications for cognition, emotion, and motivation. Psychological Review, 98, 224-253. https://doi.org/10.1037/0033-295X.98.2. 224

Mikulincer, M., \& Shaver, P. R. (Eds.). (2010). Prosocial motives, emotions, and behavior: The better angels of our nature. American Psychological Association. https://doi.org/10.1037/12061-000

Montemurro, N. (2020). The emotional impact of COVID-19: From medical staff to common people. Brain, Behavior, and Immunity, 87, 23-24. https://doi.org/10.1016/j.bbi.2020.03.032

Murray, S. L., Holmes, J. G., \& Collins, N. L. (2006). Optimizing assurance: The risk regulation system in relationships. Psychological Bulletin, 132, 641-666. https://doi.org/10.1037/00332909.132.5.641

Neel, R., Kenrick, D. T., White, A. E., \& Neuberg, S. L. (2016). Individual differences in fundamental social motives. Journal of Personality and Social Psychology, 110, 887-907. https://doi.org/10. 1037/pspp0000068
Preacher, K. J., \& Hayes, A. F. (2004). SPSS and SAS procedures for estimating indirect effects in simple mediation models. Behavior Research Methods, Instruments, \& Computers, 36, 717-731. https://doi.org/10.3758/BF03206553

Rothman, A. J., Klein, W. M., \& Weinstein, N. D. (1996). Absolute and relative biases in estimations of personal risk. Journal of Applied Social Psychology, 26, 1213-1236. https://doi.org/10. 1111/j.1559-1816.1996.tb01778.x

Russell, J. A., \& Barrett, L. F. (1999). Core affect, prototypical emotional episodes, and other things called emotion: Dissecting the elephant. Journal of Personality and Social Psychology, 76(5), 805-819. https://doi.org/10.1037/0022-3514.76.5. 805

Sedikides, C., \& Alicke, M. D. (2019). The five pillars of selfenhancement and self-protection. In R. M. Ryan (Ed.), The Oxford handbook of human motivation (2nd ed., pp. 307-319). Oxford University Press.

Sedikides, C., \& Gregg, A. P. (2008). Self-enhancement: Food for thought. Perspectives on Psychological Science, 3, 102-116. https://doi.org/10.1111/j.1745-6916.2008.00068.x

Sedikides, C., \& Strube, M. J. (1997). Self evaluation: To thine own self be good, to thine own self be sure, to thine own self be true, and to thine own self be better. In M. P. Zanna (Ed.), Advances in experimental social psychology (Vol. 29, pp. 209-269). Academic Press. https://doi.org/10.1016/S00652601(08)60018-0

Sedikides, C., Gaertner, L., \& Toguchi, Y. (2003). Pancultural selfenhancement. Journal of Personality and Social Psychology, 84, 60-79. https://doi.org/10.1037/0022-3514.84.1.60

Shaver, P. R., Mikulincer, M., \& Shemesh-Iron, M. (2010). A behavioral-systems perspective on prosocial behavior. In M. Mikulincer \& P. R. Shaver (Eds.), Prosocial motives, emotions, and behavior: The better angels of our nature (pp. 73-91). American Psychological Association. https://doi.org/10.1037/ 12061-004

Sprecher, S., \& Fehr, B. (2005). Compassionate love for close others and humanity. Journal of Social and Personal Relationships, 22, 629-651. https://doi.org/10.1177/0265407505056439

Strochlic, N. (2020). America's long history of scapegoating its Asian citizens. National Geographic. https://www.nationalgeographic. com/history/2020/09/asian-american-racism-covid/. Accessed 15 Mar 2021

Swann Jr., W. B., \& Brooks, M. (2012). Why threats trigger compensatory reactions: The need for coherence and quest for selfverification. Social Cognition, 30, 758-777. https://doi.org/10. 1521/soco.2012.30.6.758

Tappin, B. M., \& McKay, R. T. (2017). The illusion of moral superiority. Social Psychological and Personality Science, 8, 623-631. https://doi.org/10.1177/1948550616673878

Taylor, S. E., \& Brown, J. D. (1988). Illusion and well-being: A social psychological perspective on mental health. Psychological Bulletin, 103, 193-210. https://doi.org/10.1037/0033-2909. 103.2.193

Van Lange, P. A., \& Sedikides, C. (1998). Being more honest but not necessarily more intelligent than others: Generality and explanations for the Muhammad Ali effect. European Journal of Social Psychology, 28(4), 675-680. https://doi.org/10.1002/ (SICI)1099-0992(199807/08)28:4<675::AID-EJSP883>3.0. $\mathrm{CO} ; 2-5$

Wentzel, K. R., Barry, C. M., \& Caldwell, K. (2004). Friendships in middle school: Influences on motivation and school adjustment. Journal of Educational Psychology, 96, 195-203. https://doi.org/ 10.1037/0022-0663.96.2.195

Wiwad, D., \& Aknin, L. B. (2017). Motives matter: The emotional consequences of recalled self-and other-focused prosocial acts. 
Motivation and Emotion, 41, 730-740. https://doi.org/10.1007/ s11031-017-9638-2

Xu, J., Sun, G., Cao, W., Fan, W., Pan, Z., Yao, Z., \& Li, H. (2021). Stigma, discrimination, and hate crimes in Chinese-speaking world amid Covid-19 pandemic. Asian Journal of Criminology, 16, 51-74. https://doi.org/10.1007/ s11417-020-09339-8

Zell, E., Strickhouser, J. E., Sedikides, C., \& Alicke, M. D. (2020). The better-than-average effect in comparative self-evaluation: A comprehensive review and meta-analysis. Psychological Bulletin, 146, 118-149. https://doi.org/10.1037/bul0000218
Zuckerman, M. (1979). Attribution of success and failure revisited, or: The motivational bias is alive and well in attribution theory. Journal of Personality, 47, 245-287. https://doi.org/10.1111/j. 1467-6494.1979.tb00202.x

Publisher's note Springer Nature remains neutral with regard to jurisdictional claims in published maps and institutional affiliations. 